\title{
P245: Descriptive analysis of measles cases in an universitary hospital and its health area
}

\author{
S Justo Gil', T Gimenez-Julvez ${ }^{1 *}$, CA De la Hoz-Gonzalez' , A Gimenez-Cabrera'', V Muñoz-Sanz ${ }^{1}$, \\ E Rodriguez-Baena ${ }^{2}$
}

From 2nd International Conference on Prevention and Infection Control (ICPIC 2013)

Geneva, Switzerland. 25-28 June 2013

\section{Introduction}

Measles is a leading cause of vaccine-preventable childhood mortality. Despite having a vaccine with a protective efficacy of $95 \%$, outbreaks are possible if vaccination coverage is below $95 \%$. In our area there are irregular settlements where outbreaks can occur. The objetive of this paper is to describe the most relevant data of reported cases in our hospital and compare them with our health area data.

\section{Objectives}

The objetive is to describe the most relevant data of reported cases in our hospital and compare them with our health area data.

\section{Methods}

Registration in the Public Health Information System of reported cases, age, sex, serological status, hospital admission, measles vaccination status and risk group from March, $1^{\text {st }} 2009$ to September, $1^{\text {st }}$ 2011. Data were analyzed globally and by epidemiological weeks.

\section{Results}

Our hospital notified 28 (33.3\%) suspicious cases of the total area (84). Median and interquartile (IQR) age 6 years $(0.75-18.5)$ versus $7.5(1.5-18.3)$ in the area. Both modes were less than 1 year. $60.7 \%$ females in our hospital versus $58.3 \%$ females in the area. Confirmed serology hospital cases were $22(78.6 \%)$ versus $56(66.7 \%)$ area cases. 46,4\% needed hospital admission in our cases, $25 \%$ in the area.

$96.4 \%$ of the hospital cases were not vaccinated versus $92.9 \%$ in the area. $67 \%$ were from risk groups (irregular settlements and gypsy ethnic group) versus $58.3 \%$ of total area.

Incidence peak in our hospital was between 30 and 34 epidemiological weeks, later than our area (27-34 epidemiological weeks).

\section{Conclusion}

Despite appropriate vaccination coverage in the Community of Madrid, outbreaks had occurred in groups of susceptible individuals (marginal communities and children under one year who have not been vaccinated). So in 2011, the Community of Madrid came early the first-dose of measles vaccine from 15 to 12 months. Since mode is less than one year, it would be appropriate to come early the first-dose of measles vaccine between six months and a year.

\section{Disclosure of interest}

None declared.

\section{Author details \\ 'Hospital Universitario Infanta Leonor, Spain. ${ }^{2}$ Sureste Public Health Area, Madrid, Spain.}

Published: 20 June 2013

doi:10.1186/2047-2994-2-S1-P245

Cite this article as: Gil et al:: P245: Descriptive analysis of measles cases in an universitary hospital and its health area. Antimicrobial Resistance and Infection Control 2013 2(Suppl 1):P245.

${ }^{1}$ Hospital Universitario Infanta Leonor, Spain

Full list of author information is available at the end of the article

(c) 2013 Gil et al; licensee BioMed Central Ltd. This is an Open Access article distributed under the terms of the Creative Commons 